\title{
Parameter Optimization of Thermal Shrinkage Technique for Simple Numerical Simulation of Welding Angular Distortion
}

\author{
Hiroki MURAKAMI, ${ }^{1,2) *}$ Katsumasa MIYAZAKI, ${ }^{1)}$ Kenji HONNAMI, ${ }^{2)}$ Shigetaka OKANO ${ }^{2)}$ and \\ Masahito MOCHIZUKI') \\ 1) Research \& Development Group, Hitachi, Ltd., 7-1-1 Omika-cho, Hitachi, Ibaraki, 319-1292 Japan. \\ 2) Graduate School of Engineering, Osaka University, 2-1 Yamada-oka, Suita, Osaka, 565-0871 Japan.
}

(Received on November 17, 2020; accepted on April 12, 2021)

\begin{abstract}
The thermal shrinkage technique, which uses shrinkage strain to determine weld distortion, shows promise as a simple simulation for predicting the weld distortion of large welded structures. To date, there has not been adequate research on how to set input data based on welding conditions. In this work, we perform a parametric study using thermal shrinkage technique in which we vary the input data to investigate the optimum setting method. To compare angular distortion obtained by the thermal shrinkage technique, Metal active gas welding was conducted under five welding conditions and thermal elastic-plastic analysis was conducted under the same welding condition. Under all five conditions, the angular distortion obtained by the thermal shrinkage technique accurately reproduced that obtained by experiments and by thermal elastic-plastic analysis. We found that the optimum input data settings were the shrinkage strain of -0.012 and a shrinkage zone in which the maximum temperature reached $500^{\circ} \mathrm{C}$ or more. From the results, the similarity and the difference between the characteristics of angular distortion in the thermal shrinkage technique and that in the thermal elastic-plastic analysis was discussed based on the inherent strain and the moment. Moreover, the way in which inherent strain based on the both-ends-fixed-bar analogy occurred can explain the agreement in angular distortion in the case of the optimum input data settings. Our results demonstrate that a suitable setting method of input data has been established.
\end{abstract}

KEY WORDS: thermal shrinkage technique; inherent strain method; thermal elastic-plastic analysis; weld distortion; numerical simulation; finite element method; welding conditions.

\section{Introduction}

Since electrical welding was invented in the 19th century, welding has been applied to various structures such as ships, automobiles, power plants, and construction machinery. However, welding often generates geometric imperfections due to shrinkage and distortion. The geometric imperfections have negative influence on appearance of manufactured products and have the potential to decrease in structural strength due to the stress concentration. Weld distortion is usually controlled by correction using mechanical and thermal techniques, however, it takes a lot of time to correct it. Therefore, weld distortion should be appropriately and highly accurately controlled for improving productivity in manufacturing process. ${ }^{1-6)}$

In the 1970s, thermal elastic-plastic analysis using finite element methods (FEM) was first applied to welding problems. ${ }^{78)}$ Since then, various research on thermal elasticplastic analysis has been conducted for the more accurate

\footnotetext{
* Corresponding author: E-mail: hiroki.murakami.dg@hitachi.com
}

calculation of welding distortion, the understanding of the welding mechanics, and the reduction of calculation time. A simulation modelling that combined welding process and welding mechanics enabled to predict weld distortion accurately; ${ }^{9-11)}$ moreover, the dynamic substructure method, ${ }^{12)}$ the composite mesh method, ${ }^{13)}$ and idealized explicit $\mathrm{FEM}^{14,15)}$ enabled to reduce computation time and the memory consumption for calculating welding distortion. However, the application of thermal elastic-plastic analysis to production sites and design departments is not always realistic due to the long calculation time especially for large structures such as ships and construction machinery.

On the other hand, the inherent strain method and the thermal shrinkage technique, ${ }^{16,17)}$ which is a kind of the inherent strain method, have been applied to large welded structures because the calculation time is extremely short compared to thermal elastic-plastic analysis. ${ }^{18-22)}$ In addition, for reinforcement of the versatility of these methods, the research on the relationship between welding condition and the inherent strain, which is the input data in the inherent strain method. ${ }^{23,24)}$ Since the inherent strain method and 
the thermal shrinkage technique are easy to set the input data and the calculation time is extremely short compared to thermal elastic-plastic analysis, these methods are expected to be engineering useful tools for production sites and design departments.

In the thermal shrinkage technique, elastic-plastic analysis is performed using shrinkage strain and shrinkage zone, where the shrinkage strain whose value is isotropic and constant is given within the shrinkage zone. These methods require a shrinkage strain for each welding condition and each weld joint, and the way of setting input data is arbitrary. In one example, Jackson ${ }^{16)}$ previously reported the usefulness of the thermal shrinkage technique for the fillet welding of T-joints. In our own research, ${ }^{17)}$ we have applied the thermal shrinkage technique to a cylindrical structure and confirmed its usefulness. However, the two studies we mentioned set the input data in different ways. If a common setting method for input data based on welding conditions is established, the versatility of the thermal shrinkage technique will be improved, and it will be easier to use. In addition, the thermal shrinkage technique is expected to be a useful engineering tool in production sites and design departments.

The aim of this study is to establish a method for setting input data in the thermal shrinkage technique based on the welding condition. We performed a parametric study in which we varied the input data of shrinkage strain and shrinkage zone to determine which value can accurately reproduce angular distortion obtained by experiments. From the obtained results, the similarity and the difference between the characteristics of angular distortion in thermal elastic-plastic analysis and that in the thermal shrinkage technique was discussed based on the inherent strain and the moment. In addition, the generation characteristics of inherent strain in the thermal shrinkage technique using a both-ends-fixed bar analogy was clarified.

\section{Numerical Model of Thermal Shrinkage Technique}

The cause of welding shrinkage and distortion is that the thermal strain generated in the welding thermal cycle finally remains as compressive plastic strain. The thermal shrinkage technique is a simple simulation method that models this compressive plastic strain by only introducing the thermal shrinkage in the cooling process after welding, not the thermal expansion during welding. Compared with the inherent strain method based on elastic analysis, by considering the elastic-plastic behaviour in the cooling process, the thermal shrinkage technique becomes easy to set the input data. The input data are shrinkage strain (compressive strain) and the shrinkage zone which is the area where the shrinkage strain occurs, as shown in Fig. 1. Since the thermal shrinkage strain in the cooling process after welding is based on the thermal strain during welding, it is physically appropriate to set the input data in relation to the thermal expansion coefficient and temperature change that determine the thermal strain. Then, the value of shrinkage strain $\varepsilon$ is calculated by the following equation using the thermal expansion coefficient $\alpha$ and the temperature change $\Delta T$.

$$
\varepsilon=-\alpha \Delta T
$$

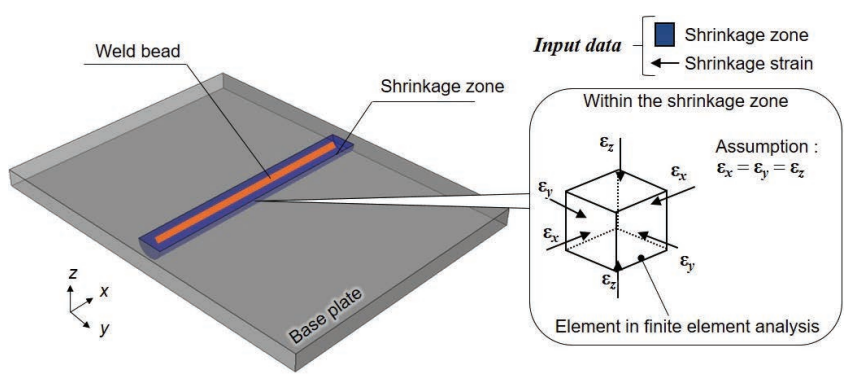

Fig. 1. Schematic illustration of thermal shrinkage technique. (Online version in color.)

Shrinkage strain is always a negative value as shown in Eq. (1) and isotropic in the three-dimensional direction. The value of shrinkage strain is constant within the shrinkage zone. Strictly speaking, the more accurate angular distortion could be obtained by applying shrinkage strain considering anisotropy in the three-dimensional direction. However, shrinkage strain is isotropic to prioritize the ease of setting the input data. Thermal expansion coefficient $\alpha$ in Eq. (1) is set to the value of those at room temperature of the material. Since the temperature change $\Delta T$ is set to an arbitrary value, the setting method needs to be decided. The shrinkage zone has an arbitrary three-dimensional shape centered on the welding line. In this study, the shrinkage zone is defined as the area where the maximum temperature of the welded plate reaches $T_{\mathrm{a}}$ or more. This is because the range of inherent strain is determined according to the maximum temperature. ${ }^{24)}$ Since the method of setting the shrinkage zone is arbitrary, the setting method needs to be decided. Since the thermal shrinkage technique calculates angular distortion by performing elastic-plastic analysis, the material properties required for the analysis are Young's modulus $E$, Poisson's ratio $v$, yield stress $\sigma_{\mathrm{Y}}$, and strain hardening coefficient $H$, whose values are those at room temperature of the material. From the above, among the parameters required to set the input data, the setting method of the temperature change $\Delta T$ and the maximum temperature $T_{\mathrm{a}}$ is arbitrary. In this study, we conducted a parameter study on these two values to establish the common setting method.

\section{Methods}

\subsection{Experimental Conditions}

We used a rolled steel for welded structure SM490YB (JIS G 3106) in the experiments. Figure 2 shows the configuration of the plate along its dimensions $(200 \mathrm{~mm}$ in length, $500 \mathrm{~mm}$ in width, and $12 \mathrm{~mm}$ in thickness). The weld length was $150 \mathrm{~mm}$, which left $25-\mathrm{mm}$ un-welded sections at both ends of the plate. The chemical composition of the steel plate is shown in Table 1. Bead-on-plate welded joints were produced by metal active gas (MAG) welding under the five welding conditions listed in Table 2. Welding current and welding speed were varied to obtain various values of angular distortion. The shield gas was $80 \%$ Ar and 20\% $\mathrm{CO}_{2}$. Angular distortion was measured using a contact-type displacement gauge after welding. Other detailed conditions in the experiments are shown in previous study. ${ }^{25}$ ) 


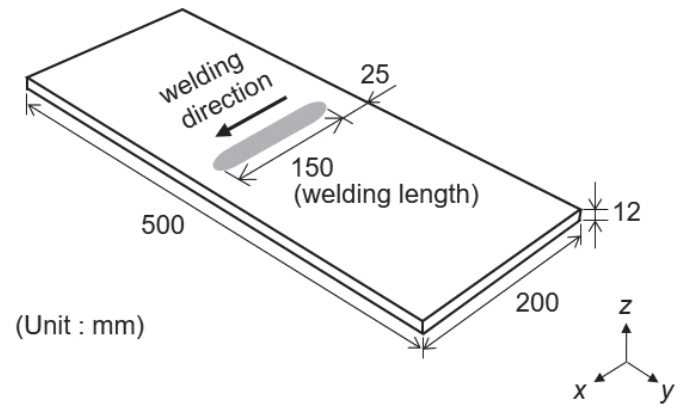

Fig. 2. Configuration of specimen to be welded.

Table 1. Chemical composition of SM490YB.

\begin{tabular}{cccccc}
\hline \multicolumn{6}{c}{ Chemical composition (mass\%) } \\
\hline $\mathrm{C}$ & $\mathrm{Si}$ & $\mathrm{Mn}$ & $\mathrm{P}$ & $\mathrm{S}$ & $\mathrm{Fe}$ \\
\hline 0.16 & 0.28 & 1.45 & 0.015 & 0.003 & Bal. \\
\hline
\end{tabular}

Table 2. Welding conditions.

\begin{tabular}{cccccc}
\hline No. & 1 & 2 & 3 & 4 & 5 \\
\hline Welding current, $I(\mathrm{~A})$ & 100 & 160 & 200 & 200 & 200 \\
Welding speed, $v(\mathrm{~mm} / \mathrm{s})$ & 3.33 & 3.33 & 3.33 & 4.67 & 6.67 \\
\hline
\end{tabular}

\subsection{Integrated Simulation Based on Thermal Elastic- plastic Analysis}

We carried out an integrated simulation of MAG welding to investigate the performance of the thermal shrinkage technique. A previous report has demonstrated that this integrated simulation model can accurately simulate weld distortion. ${ }^{9-11)}$ It consists of an arc plasma model, ${ }^{26,27)}$ a bead formation model, ${ }^{28)}$ and a stress and distortion model. In the arc plasma model, numerical simulation based on mathematical modelling of the heat transfer from arc plasma to a plate is performed to determine the heat source from the welding conditions. In the bead formation model, numerical simulation based on coupling analysis between thermal conduction and weld bead formation is performed to determine the temperature distribution and the weld bead configuration during welding from the properties of the heat source. In the stress and distortion model, numerical simulation based on thermal elastic-plastic analysis is performed to determine the weld distortion from the temperature distribution and the weld bead configuration. All the input data used in our analysis were estimated from the experimental conditions, which means no preliminary experiment was required. We carried out the integrated simulation under the welding conditions shown in Table 2. More detailed information regarding input data used in the integrated simulation is shown in the previous study. ${ }^{29)}$

\subsection{Thermal Shrinkage Technique}

The configuration of the analytical model was the same as that of the experiment shown in Fig. 2. The material properties used are shown in Table 3. Parametric study of the thermal shrinkage technique was performed under the 12 conditions listed in Table 4. Shrinkage strain $\varepsilon$ is calculated by the product of thermal expansion coefficient $\alpha$ and the
Table 3. Material properties used for thermal shrinkage technique.

\begin{tabular}{c|c}
\hline Young's modulus, $E(\mathrm{GPa})$ & 210 \\
Poisson's ratio, $v$ & 0.3 \\
Yield stress, $\sigma_{\mathrm{y}}(\mathrm{MPa})$ & 417 \\
Strain hardening coefficient, $H(\mathrm{MPa})$ & 970 \\
\hline
\end{tabular}

Table 4. Numerical conditions of thermal shrinkage technique.

\begin{tabular}{ccccc}
\hline No. & $\begin{array}{c}\text { Shrinkage } \\
\text { strain, } \varepsilon\end{array}$ & $\begin{array}{c}\text { Thermal } \\
\text { expansion } \\
\text { coefficient, } \alpha\end{array}$ & $\begin{array}{c}\text { Temperature } \\
\text { change, } \Delta T\end{array}$ & $\begin{array}{c}\text { Shrinkage } \\
\text { zone, } T_{a}\end{array}$ \\
\hline 1 & $-3.60 \times 10^{-3}$ & $1.2 \times 10^{-5}$ & 300 & 500 \\
2 & $-6.00 \times 10^{-3}$ & $1.2 \times 10^{-5}$ & 500 & 500 \\
3 & $-9.60 \times 10^{-3}$ & $1.2 \times 10^{-5}$ & 800 & 500 \\
4 & $-1.20 \times 10^{-2}$ & $1.2 \times 10^{-5}$ & 1000 & 500 \\
5 & $-1.44 \times 10^{-2}$ & $1.2 \times 10^{-5}$ & 1200 & 500 \\
6 & $-1.80 \times 10^{-2}$ & $1.2 \times 10^{-5}$ & 1500 & 500 \\
\hline 7 & $-3.60 \times 10^{-3}$ & $1.2 \times 10^{-5}$ & 300 & 800 \\
8 & $-6.00 \times 10^{-3}$ & $1.2 \times 10^{-5}$ & 500 & 800 \\
9 & $-9.60 \times 10^{-3}$ & $1.2 \times 10^{-5}$ & 800 & 800 \\
10 & $-1.20 \times 10^{-2}$ & $1.2 \times 10^{-5}$ & 1000 & 800 \\
11 & $-1.44 \times 10^{-2}$ & $1.2 \times 10^{-5}$ & 1200 & 800 \\
12 & $-1.80 \times 10^{-2}$ & $1.2 \times 10^{-5}$ & 1500 & 800 \\
\hline & & & &
\end{tabular}

temperature change $\Delta T$, shown in Eq. (1). Thermal expansion coefficient $\alpha$ was set to $1.2 \times 10^{-5}$, which is the value of the thermal expansion coefficient of SM490YB in room temperature. The temperature change $\Delta \mathrm{T}$ was set to $300^{\circ} \mathrm{C}$, $500^{\circ} \mathrm{C}, 800^{\circ} \mathrm{C}, 1000^{\circ} \mathrm{C}, 1200^{\circ} \mathrm{C}$, and $1500^{\circ} \mathrm{C}$. Therefore, six values of shrinkage strain $\varepsilon$ were used: $-3.60 \times$ $10^{-3},-6.00 \times 10^{-3},-9.60 \times 10^{-3},-1.20 \times 10^{-2},-1.44 \times$ $10^{-2}$, and $-1.80 \times 10^{-2}$. We defined the shrinkage zone as the area where the maximum temperature of the welded plate reaches $T_{\mathrm{a}}$ or more and set it to two values $\left(T_{\mathrm{a}}=500\right.$, 800). The temperature $T_{\mathrm{a}}$ was determined by the maximum temperature obtained by the integrated simulation model discussed in the previous section.

\section{Results}

\subsection{Comparison of Angular Distortion}

First, we evaluated the angular distortion at the center of the plate in the welding direction. A comparison of the angular distortion obtained by the thermal shrinkage technique, the experiment, and the thermal elastic-plastic analysis is shown in Fig. 3. We found that the angular distortion in the thermal shrinkage technique increased with an increase in temperature change $\Delta T$ and decrease in the temperature $T_{\mathrm{a}}$; in other words, angular distortion increased with an increase in the shrinkage strain and the shrinkage zone. In the case of temperature $T_{\mathrm{a}}=500$ and temperature change $\Delta T=1000$, the angular distortion obtained by the thermal shrinkage technique was in good agreement with that obtained by experiments and the thermal elastic-plastic analysis under all five welding conditions. Based on the 

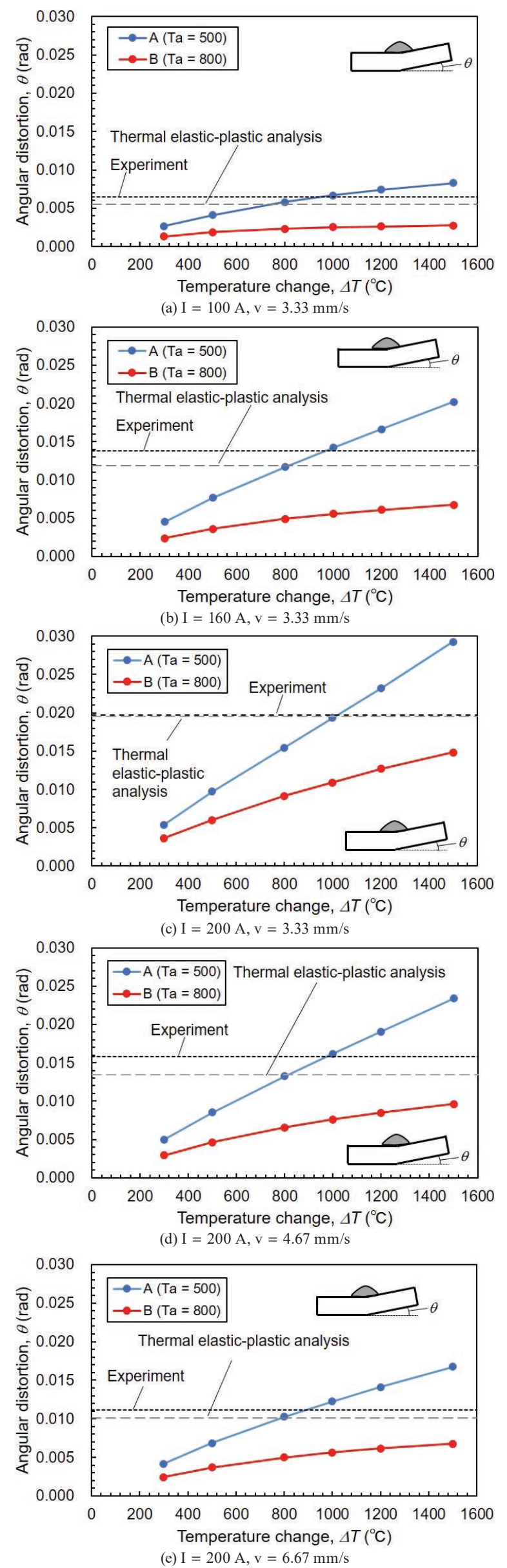

Fig. 3. Comparison of angular distortion among thermal shrinkage technique, thermal elastic-plastic analysis, and experiment. (Online version in color.) tendency mentioned above, a combination other than temperature change $\Delta T=1000$ and maximum temperature $T_{\mathrm{a}}=500$ may reproduce the experimental results, however, we discuss the mechanism behind angular distortion in case temperature change $\Delta T=1000$ and maximum temperature $T_{\mathrm{a}}=500$ in the following section.

\section{Discussion}

\subsection{Mechanism Behind Angular Distortion}

Next, in order to clarify the cause that the angular distortion obtained by the thermal shrinkage technique was in good agreement with that obtained by experiments and the thermal elastic-plastic analysis, we discuss here the inherent strain distribution and the moment, which are dominant factors of angular distortion. ${ }^{24)}$ Here, the inherent strain, which is derived by subtracting the elastic strain from the apparent strain, is equal to the plastic strain perpendicular to the welding direction. Figure $\mathbf{4}$ shows the inherent strain (plastic strain) distributions under the welding condition $I=200 \mathrm{~A}, v=3.33 \mathrm{~mm} / \mathrm{s}$ (the results under the other four conditions showed the same tendency). As shown in Figs. 4(a) and 4(b), there were significant differences in the inherent strain distribution between the thermal shrinkage technique and the thermal elastic-plastic analysis. In Fig. 4(a), tensile strain occurred at $y=10 \mathrm{~mm}$ in the thermal shrinkage technique, whereas compressive strain occurred from $y=0$ to $10 \mathrm{~mm}$ in the thermal elastic-plastic analysis. In Fig. 4(b), at about $z=3 \mathrm{~mm}$, the inherent strain obtained by the thermal elastic-plastic analysis was about twice as big

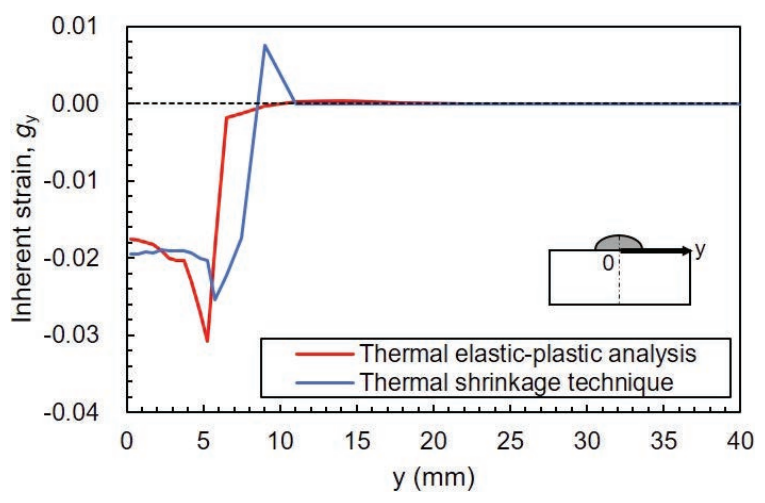

(a) Transverse direction (y-direction)

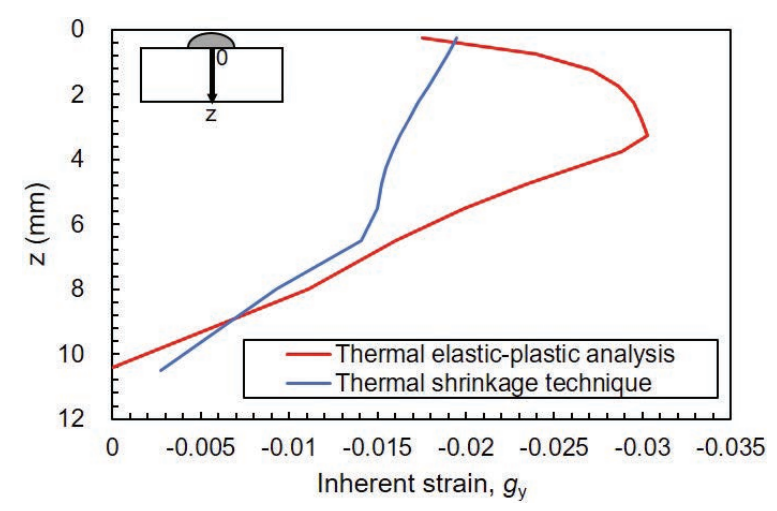

(b) Thickness direction (z-direction)

Fig. 4. Comparison of inherent strain between thermal shrinkage technique and thermal elastic-plastic analysis. (Online version in color.) 
as that obtained by the thermal shrinkage technique. These results demonstrate that the agreement in angular distortion among the thermal shrinkage technique, the experiment, and thermal elastic-plastic analysis was not due to the inherent strain distribution.

We next considered the moment as a possible cause of the agreement in angular distortion because the moment generated by the difference in shrinkage is known to be the driving force of angular distortion. The schematic illustration of the moment is shown in Fig. 5. After welding, $y$-direction compressive plastic strain (inherent strain) remains near the welded zone. This causes the plate to shrink in the $y$-direction. When the shrinkage is unevenly distributed in the plate thickness direction (z-direction), out-of-plane distortion, which is called angular distortion, is generated due to the moment based on the center of the plate thickness. Generally, the moment $M$ is represented by the following equation using the load $F$ and the distance from the center of the plate thickness $L$.

$$
M=F L
$$

The load $F$ was calculated by the following equation using the area A, Young's modulus $E$, and strain in element ( $\varepsilon=$ $\Delta l / l)$.

$$
F=(A E) \cdot(\Delta l / l)
$$

Here, since the element size (area $A$, element length $l$ ) and Young's modulus $E$ are the same in both methods, the shrinkage $\mathrm{S}(=\Delta l)$ is expressed by the following equation.

$$
S(=\Delta l)=\Sigma g_{i} l_{i}
$$

where $l_{i}$ is a length of the element perpendicular to the welding direction and $g_{i}$ is the inherent strain in the element. We compared shrinkage $S$ in the thermal shrinkage technique with that in the thermal elastic-plastic analysis (Fig. 6) and found that it was about $10 \%$ to $20 \%$ larger in the former. This explains why the angular distortion obtained by the thermal shrinkage technique was about $10 \%$ to $20 \%$ larger than that obtained by the thermal elastic-plastic analysis (Fig. 3). This means that, even if we do not strictly reproduce an actual inherent strain distribution, the angular distortion could be accurately predicted by reproducing a moment. This indicates that the thermal shrinkage technique has potential as a useful tool in the simple numerical simulation model of weld distortion.

\subsection{Theoretical Verification of Shrinkage Strain Set- ting}

To theoretically explain the agreement in angular distortion, here we discuss the generation characteristics of inherent strain in the thermal shrinkage technique by means of a both-ends-fixed bar analogy. ${ }^{30)}$ Specifically, we compare the inherent strain based on the both-ends-fixed bar analogy (hereinafter referred to as theoretical inherent strain) and the inherent strain derived from the temperature distribution based on the thermal shrinkage technique (hereinafter referred to as mean inherent strain).

First, we derived the theoretical inherent strain $g_{y_{s} s}$. In the both-ends-fixed bar analogy, the apparent strain $\varepsilon$ is represented by the following equation using the elastic strain $\varepsilon_{e}$ and the plastic strain $\varepsilon_{p}$ and the thermal strain $\varepsilon_{t}$.

$$
\varepsilon=\varepsilon_{e}+\varepsilon_{p}+\varepsilon_{t}
$$

In the case where the shrinkage strain $\left(\varepsilon_{t}=\right) \alpha \Delta T_{s}$ was given

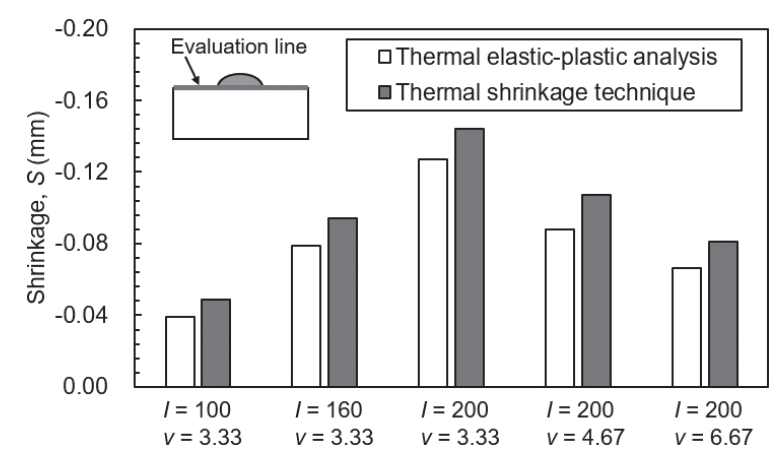

(a) Evaluation line: plate surface

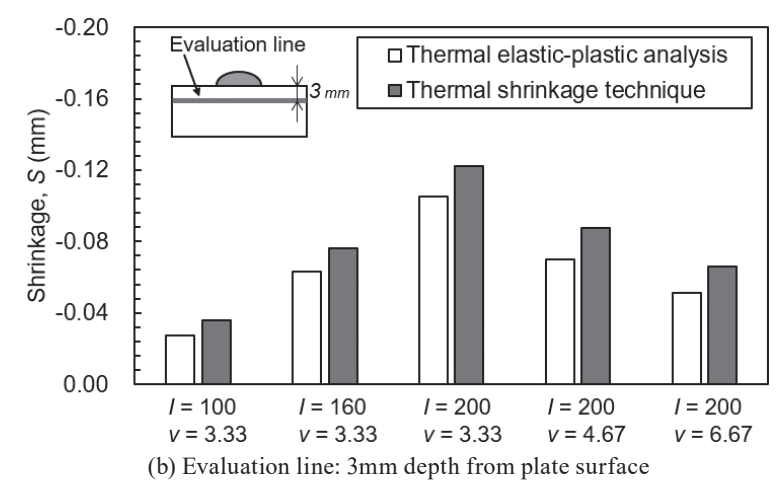

Fig. 6. Comparison of shrinkage between thermal shrinkage technique and thermal elastic-plastic analysis.

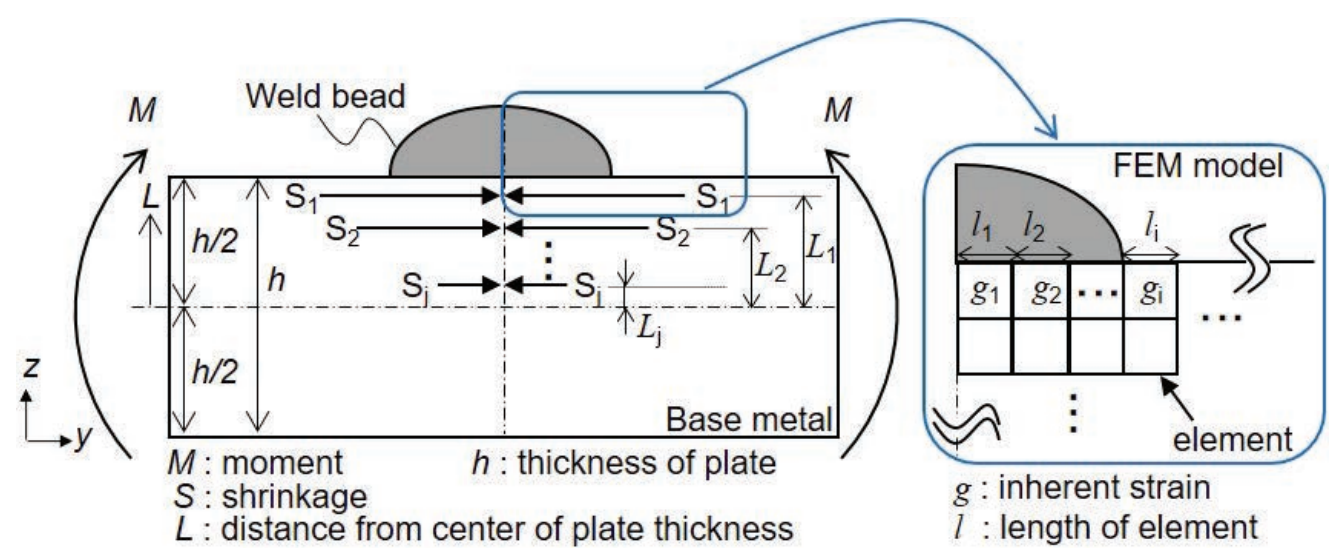

Fig. 5. Schematic illustration of the moment. (Online version in color.) 
to the both-ends-fixed bar, the apparent strain $\varepsilon$ is represented by the following equation using the elastic strain $\varepsilon_{e}$ and the plastic strain $\varepsilon_{p}$.

$$
\varepsilon=\varepsilon_{e}+\varepsilon_{p}-\alpha \Delta T_{s}
$$

In Eq. (6), the apparent strain $\varepsilon$ is zero in the welding direction ( $x$ direction) because the restraint is strong. In the case where the both-ends-fixed bar was yielded due to the given shrinkage strain, the plastic strain in the welding direction $\varepsilon_{p x}$ is represented by the following equation using yield strain $\varepsilon_{Y}\left(=\sigma_{Y} / E\right)$.

$$
\varepsilon_{p x}=\alpha \Delta T_{s}-\varepsilon_{Y}
$$

The plastic strain in welding direction $\varepsilon_{p x}$, perpendicular to welding direction $\varepsilon_{p y}$, and in thickness direction $\varepsilon_{p z}$ can be represented by the following approximate equation under constant volume.

$$
\varepsilon_{p x}+\varepsilon_{p y}+\varepsilon_{p z}=0
$$

Assuming that the degree of restraint perpendicular to the welding direction and that in the thickness direction is equal, the plastic strain perpendicular to the welding direction $\varepsilon_{p y}$ is represented by the following equation.

$$
\varepsilon_{p y}=-0.5 \varepsilon_{p x}
$$

Since, the inherent strain $g$ was derived by subtracting the elastic strain $\varepsilon_{e}$ from the apparent strain $\varepsilon$, the inherent strain $g_{y_{-} s}$ perpendicular to the welding direction ( $y$ direction) is represented by the following equation.

$$
g_{y_{-} s}=\varepsilon_{p y}-\alpha \Delta T_{s}
$$

The inherent strain $g_{y_{-} s}$ was thus derived by Eqs. (7), (9).

$$
g_{y_{-} s}=0.5 \varepsilon_{Y}-1.5 \alpha \Delta T_{s}
$$

Under the condition used in this study $\left(E=200000, \sigma_{Y}=\right.$ 417, $\left.\alpha=1.2 \times 10^{-5}, \Delta T_{s}=1000\right)$, the inherent strain $g_{y_{-} s}$ was -0.017 .

Second, we derived the mean strain $g_{y_{-} t}$ from the temperature distribution. Temperature distribution was generated in the plate during welding (shown in the red line in Fig. 7). Angular distortion can be obtained by the strain corresponding to the temperature rise. Since the thermal shrinkage technique gives the constant thermal strain as a shrinkage strain as shown in Eq. (1), it could be equivalent to applying a constant temperature rise $\Delta T_{t}$ given in a certain area $w$, as shown in the blue line in Fig. 7. We assume here that all the expansion in the heating process contributed to the inherent strain (angular distortion). In other words, the inherent strain perpendicular to the welding direction (y direction) is represented by the following equation.

$$
g_{i}=-\alpha \Delta T_{i}
$$

Using the results of the thermal elastic-plastic analysis, we calculated the mean strain $g_{y_{t}}$ by

$$
g_{y_{-} t}=-\alpha \sum \Delta T_{i} / w
$$

where the width $w$ is where the temperature reaches $500^{\circ} \mathrm{C}$ ( $=T_{\mathrm{a}}$ ). Figure 8 shows a comparison of the theoretical inherent strain $g_{y_{-} s}$ and the mean inherent strain $g_{y_{-} t}$ under the five welding conditions. The absolute value of the mean strain was about $10 \%$ larger than that of the theoretical

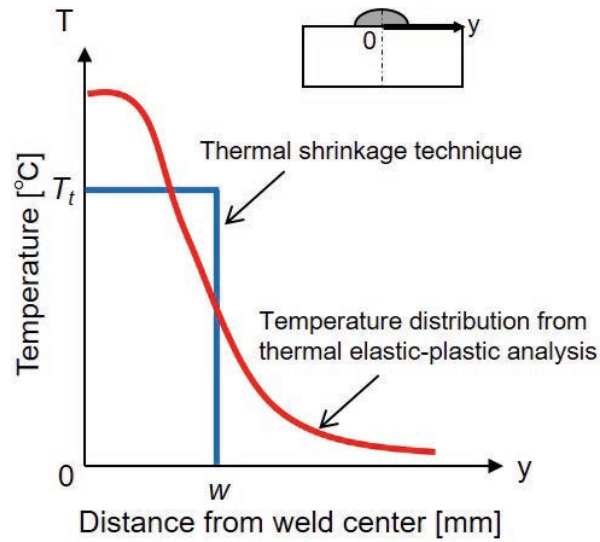

Fig. 7. Schematic illustration of temperature distribution. (Online version in color.)

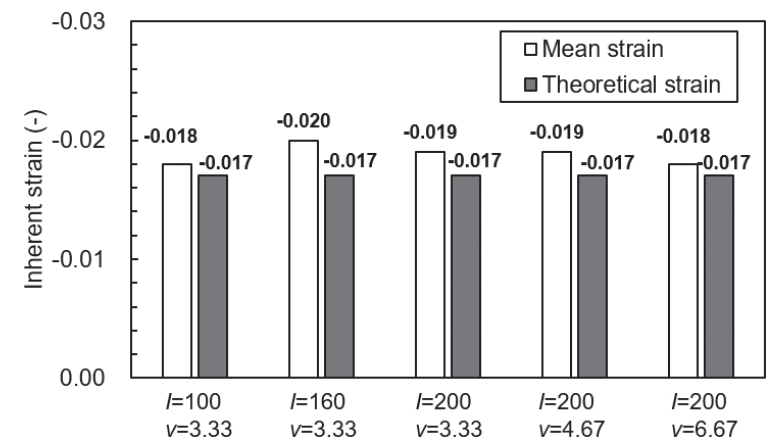

Fig. 8. Comparison of theoretical strain and mean strain.

strain. Strictly speaking, the strain caused by the heating process was not equal to the inherent strain. In addition, the influence of the elastic strain needed to be considered in determining the inherent strain in Eq. (12). The mean strain, however, was in good agreement with the theoretical strain under all five conditions.

As shown above, the way in which inherent strain based on the both-ends-fixed-bar analogy occurred can explain the agreement in angular distortion in the case of temperature $T_{\mathrm{a}}=500$ and temperature change $\Delta T=1000$. It could be considered that the thermal shrinkage technique with the proposed setting method is thus applied to other welding conditions. In the case of single welding, the usefulness of the thermal shrinkage technique with the proposed setting method was shown in this paper, but additional study could be required for the application of the proposed setting method to multi-layer welding. The proposed setting method could also be applied to other material (e.g. carbon steel) in case the thermal expansion coefficient used to calculate the inherent strain (Eq. (12)) and the thermal conductivity, density, and specific heat used to calculate the maximum temperature (the shrinkage zone) are almost the same as SM490YB. Overall, our findings demonstrate that the thermal shrinkage technique could be highly effective for predicting weld distortion.

\section{Conclusion}

In this work, we performed a parametric study to investigate input data that can reproduce angular distortion in 
experiments to establish a method of setting data in the thermal shrinkage technique. From the obtained results, the mechanism behind angular distortion obtained by the thermal shrinkage technique was discussed based on the inherent strain and the moment. In addition, the generation characteristics of inherent strain in the thermal shrinkage technique using a both-ends-fixed bar analogy was discussed. Our main findings are as follows.

(1) We identified the optimum input data $(\Delta T=1000$, $\left.T_{\mathrm{a}}=500\right)$ for SM490YB in the thermal shrinkage technique that can reproduce angular distortion obtained by experiments under five welding conditions.

(2) From the discussion of the inherent strain distribution and the moment, we clarified that even if we do not strictly reproduce an actual inherent strain distribution, the angular distortion could be accurately predicted by reproducing a moment.

(3) In the case of the optimum input data settings of the thermal shrinkage technique, the occurrence of inherent strain based on the both-ends-fixed-bar analogy explained the agreement in angular distortion among the thermal shrinkage technique, the thermal elastic-plastic analysis, and the experiments.

\section{REFERENCES}

1) T. Miyata: J. Jpn. Weld. Soc. 52 (1983), 606 (in Japanese).

2) T. Yamakawa: J. Jpn. Weld. Soc., 67 (1998), 121 (in Japanese).

3) P. Michaleris: Minimization of Welding Distortion and Buckling: Modelling and Implementation, Woodhead Publishing Limited, Cambridge, UK, (2011), 1.

4) T. Gray, D. Camilleri and N. McPherson: Control of Welding Distortion in Thin-Plate Fabrication: Design Support Exploiting Computational Simulation, Woodhead Publishing Limited, Cambridge, UK, (2014), 1.

5) S. Okano and M. Mochizuki: ISIJ Int., 56 (2016), 647.

6) M. Tsunori, M. Mouri, S. Sasou and H. Kusumoto: J. Light Met.
Weld., 58 (2020), 31 (in Japanese).

7) Y. Ueda and N. Ma: Q. J. Jpn. Weld. Soc., 11 (1993), 189 (in Japanese).

8) Y. Fujita and T. Nomoto: J. Jpn. Weld. Soc., 45 (1976), 22 (in Japanese).

9) S. Okano, M. Tanaka and M. Mochizuki: Sci. Technol. Weld. Join., 16 (2011), 209.

10) S. Okano, F. Miyasaka, M. Tanaka and M. Mochizuki: Q. J. Jpn. Weld. Soc., 32 (2014), 276 (in Japanese)

11) S. Okano and M. Mochizuki: ISIJ Int., 57 (2017), 511.

12) S. Brown and H. Song: Weld. J., 71 (1992), 55-s.

13) J. Goldak, M. Mocanita, V. Aldea, J. Zhou, D. Downey and D. Dorling: Proc. ASME Pressure Vessels and Piping Conf., Vol. 410, ASME, New York, (2000), 21.

14) K. Ikushima, S. Itoh and M. Shibahara: Q. J. Jpn. Weld. Soc., 31 (2013), 23 (in Japanese).

15) K. Ikushima and M. Shibahara: J. Offshore Mech. Arct. Eng., 141 (2019), 021603.

16) K. Jackson and R. Darlington: IOP Conf. Ser. Mater. Sci. Eng., 26 (2011), 012018

17) H. Murakami, T. Terasaki, K. Miyazaki, Y. Maeda, S. Okano and M. Mochizuki: J. High Press. Inst. Jpn., 58 (2020), 93 (in Japanese).

18) D. Deng, H. Murakawa and N. Ma: Sci. Technol. Weld. Join., 17 (2012), 13 .

19) J. Wang, S. Rashed, H. Murakawa and Y. Luo: Mar. Struct., 34 (2013), 135.

20) O. Gupta: Sci. Technol. Weld. Join., 23 (2018), 428.

21) N. Ma, J. Tateishi, S. Hiroi, A. Kunugi and H. Huang: Q. J. Jpn. Weld. Soc., 35 (2017), 137s (in Japanese).

22) A. Honaryar, M. Iranmaesh, P. Liu and A. Honaryar: Ocean Eng., 200 (2020), 106976

23) H. Murakawa, Y. Luo and Y. Ueda: J. Soc. Nav. Archit. Jpn., 1996 (1996), No. 180, 739 (in Japanese).

24) M. Mochizuki and S. Okano: Trans. Jpn. Soc. Mech. Eng., 82 (2016), 15-00567 (in Japanese).

25) S. Okano, K. Matsushita, M. Mochizuki, M. Toyoda and T. Ueyama: Q. J. Jpn. Weld. Soc., 28 (2010), 97 (in Japanese).

26) M. Hermans and G. den Ouden: Sci. Technol. Weld. Join., 3 (1998), 135.

27) Y. Tsujimura and M. Tanaka: Q. J. Jpn. Weld. Soc., 30 (2012), 68 (in Japanese).

28) F. Miyasaka, Y. Yamane and T. Ohji: Q. J. Jpn. Weld. Soc., 22 (2004), 487 (in Japanese).

29) M. Mochizuki and S. Okano: ISIJ Int., 58 (2018), 153.

30) K. Satoh and T. Ohnishi: J. Jpn. Weld. Soc., 38 (1969), 359 (in Japanese). 